Portland State University

PDXScholar

$12-2-1992$

\title{
Connected Painted Rectangles Experiments in Quantitative Shape and Contrasting Elements
}

Ann Shiogi

Portland State University

Follow this and additional works at: https://pdxscholar.library.pdx.edu/open_access_etds

Part of the Painting Commons

Let us know how access to this document benefits you.

\section{Recommended Citation}

Shiogi, Ann, "Connected Painted Rectangles Experiments in Quantitative Shape and Contrasting Elements" (1992). Dissertations and Theses. Paper 4670.

https://doi.org/10.15760/etd.6553

This Thesis is brought to you for free and open access. It has been accepted for inclusion in Dissertations and Theses by an authorized administrator of PDXScholar. Please contact us if we can make this document more accessible: pdxscholar@pdx.edu. 
AN ABSTRACT OF THE THESIS OF Ann Shiogi for the Master of Fine Arts in Art: Painting presented December 2, 1992.

Title: Connected Painted Rectangles Experiments in Quantitative Shape and Contrasting Elements.

APPROVED BY MEMBERS OF THE THESIS COMMITTEE:

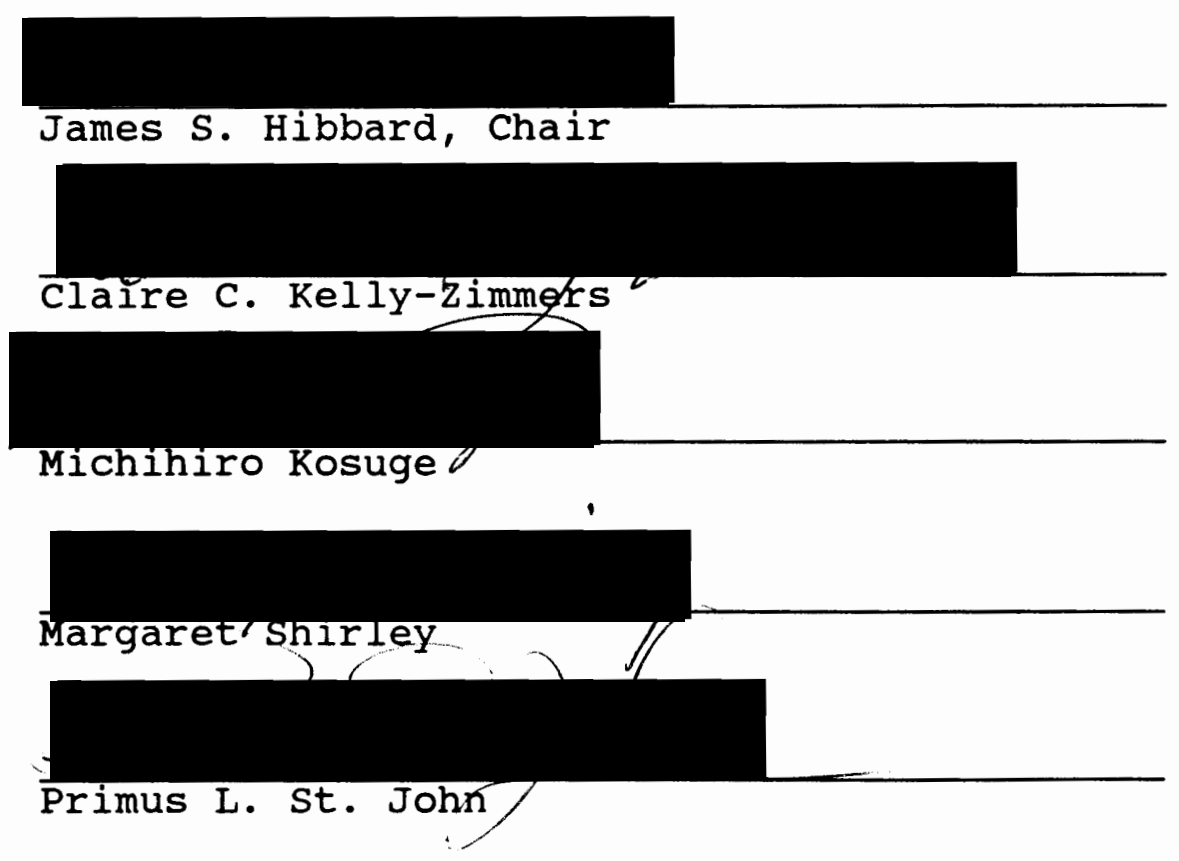

The thesis consisted of a series of paintings in which the canvases were individually painted in a predetermined way, then arranged and assembled more spontaneously in a final wall construction. Narrow limitations, such as working with only horizontal and vertical compositions and contrasting colors were specified. By working within a 
method or procedure, and by remaining strict to these guidelines, the ideas inherent in the paintings emerged and were then promoted.

The dominant ideas that developed out of the process of making the paintings were the use of both "found" shapes -found in leftover lengths of support material_and "found" means of dividing the canvas, found in statistical information culled from current events in the newspaper. Also, the idea of unifying the painting with contrasting shapes, colors, surfaces, and values arose out of the process.

The actual results of the painting process became clearer during the "spontaneous assembling of the paintings." The final wall constructions were made by arranging the individual canvases in different configurations and then mounting them on the wall. After the paintings went to the wall, possibilities for alteration and how they interacted with the wall could be seen. 


\title{
CONNECTED PAINTED RECTANGLES EXPERIMENTS \\ IN QUANTITATIVE SHAPE AND \\ CONTRASTING ELEMENTS
}

\author{
by \\ ANN SHIOGI
}
A thesis submitted in partial fulfillment of the requirements for the degree of
MASTER OF FINE ARTS in
ART: PAINTING

Portland State University

1993 
TO THE OFFICE OF GRADUATE STUDIES:

The members of the Committee approve the thesis of Ann Shiogi presented December 2, 1992 .
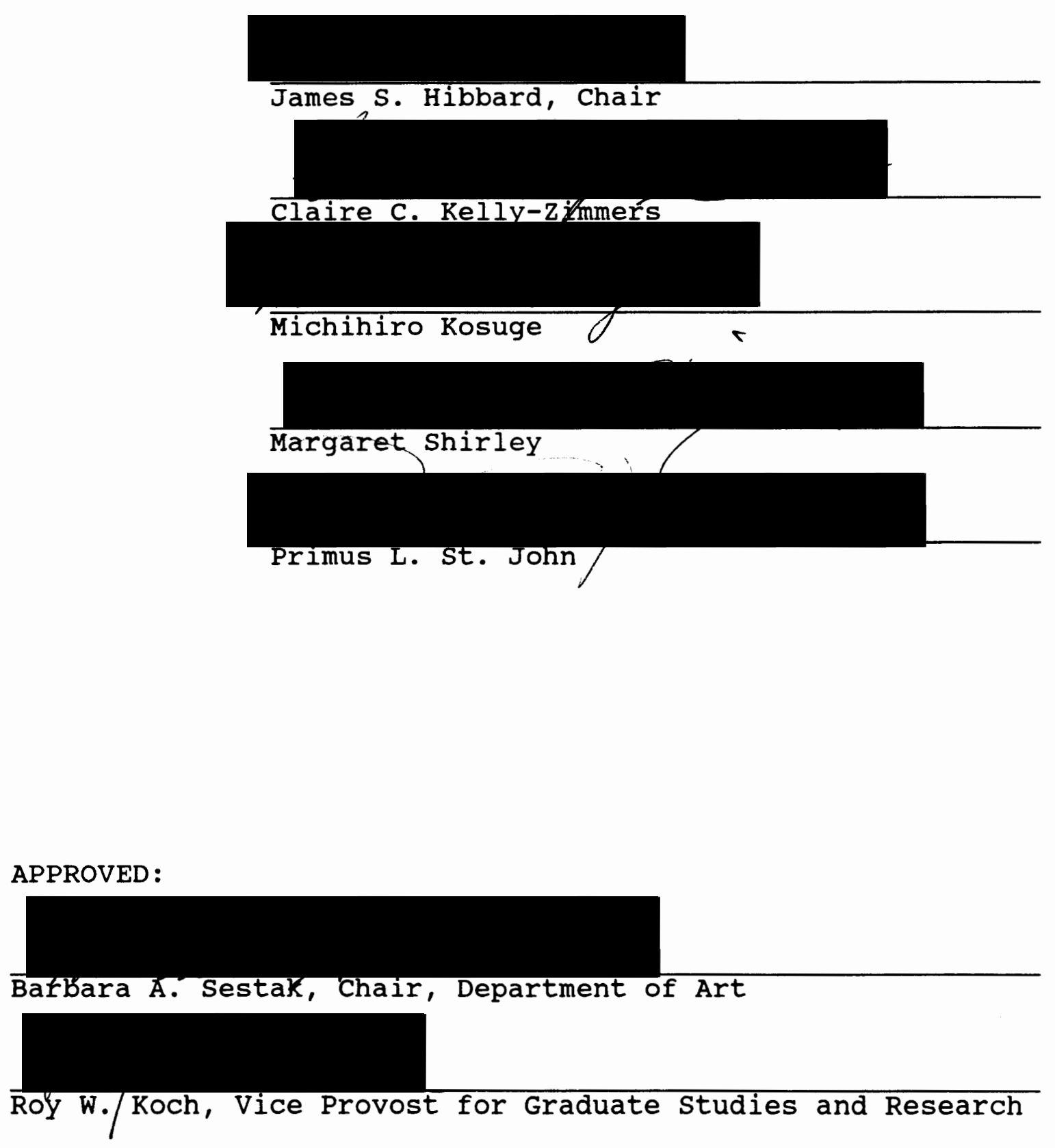
TABLE OF CONTENTS

PAGE

LIST OF FIGURES . . . . . . . . . . . . . . . . . . . iv

CHAPTER

I THE PAINTING PROCESS . . . . . . . . . . . 1

Introduction $\quad$. . . . . . . . . 1

Conceptual Basis . . . . . . . . . 2

Found Shapes

Found Divisions

Unity Through Contrast

Paint and color . . . . . . . . 6

Paint

Color

Final Assembly

CHAPTER

II PERSONAL CONTEXT

CHAPTER

III THE PAINTINGS $\quad$ • . . . . . . . . . . . 12

$5 \% \neq 50 \%$

Untitled \#1

Untitled \#6

Untitled \#3

Untitled \#5

Baby Got Back

Untitled \#7

Conclusion $\quad . \quad \cdot$. . . . . . . . . . 


\section{LIST OF FIGURES}

FIGURE

PAGE

1 Untitled Diagram . . . . . . . . . . . . 4

$2 \quad 5 \% \neq 50 \%\left(75^{\prime \prime} \times 75^{\prime \prime}\right) \quad$. . . . . . . . 12

3 Untitled \#1 (31 1/2" x 59") . . . . . . . . 14

4 Untitled \#6 (48" x 67") . . . . . . . . . 15

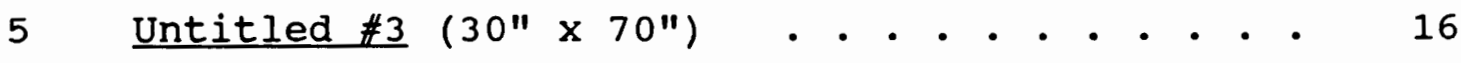

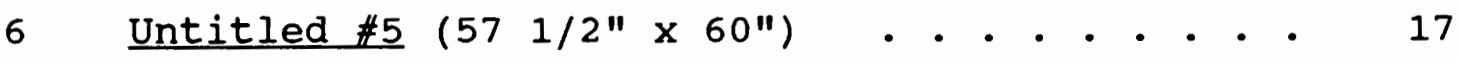

7 Baby got back (73" $\times 533 / 4 ") \quad$. . . . . . . 18

8 Untitled $\# 7\left(351 / 2 " \times 36^{\prime \prime}\right) \quad . \quad . \quad . \quad . \quad . . . \quad 19$ 
CHAPTER I

THE PAINTING PROCESS

\section{INTRODUCTION}

For the terminal project in the master's program, I proposed a series of paintings in which the canvases would be individually painted in a predetermined way, then arranged and assembled more spontaneously in a final wall construction. In my proposal I specified narrow limitations, such as working with only horizontal and vertical compositions and contrasting colors. I thought I needed a method or procedure to work within; and by remaining strict to these guidelines the ideas inherent in the paintings would emerge and could be promoted. These were the assumptions with which I began.

\section{CONCEPTUAL BASIS}

The dominant ideas that developed out of the process of making the paintings were the use of both "found" shapes and "found" means of dividing the canvas. Also, the idea of unifying the painting with contrasting shapes, colors, surfaces, and values arose out of the process. 


\section{Found Shapes}

Using found material in art is an idea I associate with synthetic cubism. Its use can broaden the scope of pictorial possibilities by allowing the artist to involve the material in both a literal and a subjective way. In Picasso's Man with a Hat, for example, the unincorporated newspaper describes the plane of a man's face yet remains true to the flatness of the surface, all the while suggesting itself and the contents of the printed page.

At the outset, I tried to use the golden rectangle as a shape for my canvases. This seemed to me to be "starting off on the right foot." There is no question in my mind that this is an ideal proportion, which has been reaffirmed throughout history and in scientific research. One can refer to classical Greek architecture or Fibonacci numbers as two examples of the many uses of the golden proportion. However, I was using eight-foot lumber to make my stretcher bars-a length common to commercial building-so in realizing a golden proportion, I would end up with leftover lumber.

As time passed, I became more interested in the shapes made by the leftover pieces. These proportions are the residue of a specific choice, and very much related to what makes an ideal proportions. It is the negative space, as it were. 
So, I came to use found materials-scrap lumber-as a way of arriving at the actual shape of the canvas; to explore alternative shapes and to bring my work closer to the "real" world, not remaining in the calculated world of pure abstraction.

\section{Found Divisions}

Although many of the canvases remained undivided, I chose simple divisions for others. I used statistical information to determine where to make the cut; in a sense, using a "found" division. The purpose of using statistics was to find a subject that shared a reduced form similar to the painting method. That is, both statistical information and abstract painting can be seen as "reductive distillations."

I culled statistics from the news about events that I thought were interesting, and used them by taking a percentage of the total surface area of the canvas and painting it a different color from the remainder. For instance, 24 percent of the Allied Persian Gulf War fatalities were from friendly fire. The interpretation of this statistic in a painting might look like this (Figure 1).

I usually began with the statistic rather than finding a statistic that would make an interesting shape. some of my canvases never left the studio, so not all of the 


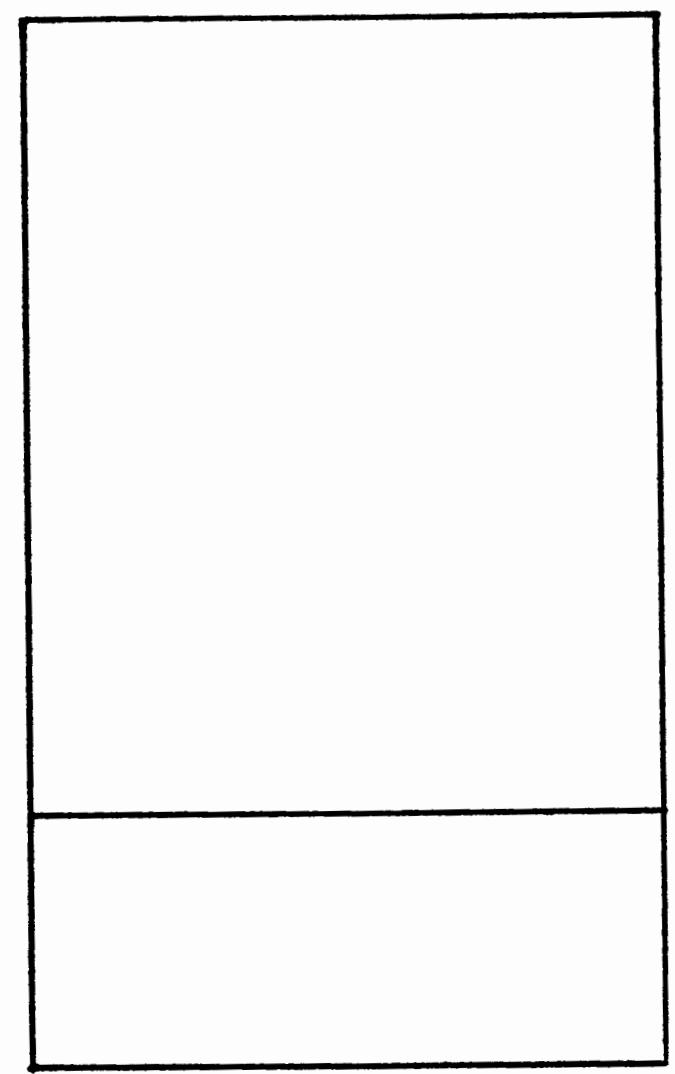

Figure 1. Untitled Diagram.

statistics I used made it to the final thesis project. I did not try to make the color or the surface relate to the statistical information, which is something I now regret. As in the use of scrap lumber, the statistic seems to me to somehow extend the painting in the world outside the studio and art history. But their use should be seen as a tool -the paintings are not about the statistics. 
The effect of using the statistic was to create an unselfconscious beginning. It was a way to remove myself slightly from specific decision making. It is very much like drawing from a still life model where the information before you is already determined. In this case, I had exact information which allowed for simple execution, although I wasn't sure how the completed paintings would turn out.

\section{Unity Through contrast}

The concept of unifying a painting with contrasting elements is a variant on the ideas originated in the teachings of Hans Hoffman. "Push/pull," where the painting reconciles illusionistic depth and actuality of surface in the manipulation of color relationships, became for me a concept that I could extend to different aspects of the painting process. I could use contrast to knit the painting together visually and theoretically. For example, since my proposal had strong references to contrast, I thought I could apply this concept to the shape-making process. I was getting a lot of long, narrow rectangles from leftover lumber. So to invoke contrast, I simply built more square shapes.

Despite the aesthetic effect, I decided to use thicker supports. I did this for a practical reason because the thicker wood has greater structural stability. The thicker supports gives the painting a greater relief from the wall, 
implying a sculptural presence. When the painting becomes an object rather than the traditional window, the surface asserts itself with a greater physicality. This quality can be promoted or negated by the artist, providing another basis for contrast.

\section{PAINT AND COLOR}

\section{Paint}

After stretching the canvas over the completed supports and applying rabbit skin glue and commercial gesso, my thinking turned to the paint surface. What makes a believable paint surface? It seemed to me that an answer was a direct application of a layer of paint, put down in an uncontrived and unlabored way. If one layer seemed unsatisfactory, then another layer could be applied until the surface became quite thick.

Although I admire thin applications of paint, such as the work of Mark Rothko, I did not want to preserve a precious surface or promote hesitancy in applying paint. I wanted a paint surface not unlike the lines painted on streets and highways, where the paint is thin and thick from multiple applications.

I decided to apply paint with a palette knife and use a wax medium and pumice powder to create contrast in the texture of the paint film and to coincide with the dimensional aspects of a thicker support. Applying paint 
with a knife seemed like the most direct way to achieve an uncomplicated paint layer while yet remaining receptive to additional layers as needed. As the paint surface began to build up, I felt it was appropriate to allow the layers beneath the top coat to show through. Whether one senses a history of the painting process or not, the layered application gives the surface a casualness which I hoped to contrast the hardness of the shape and structure.

\section{Color}

Prior to my involvement in this program, I had not really worked with color, so when confronted with color choices I tried to remain within the primary and secondary color palette. Although a primary/secondary color palette is very rich and intense, it also offers a clear broad value range. Given limited areas of color, from the compositional break up of the statistical information, it seemed as though a primary/secondary palette would provide distinct value differences. Since I wasn't trying to match a set of colors from observation and the color relationships would develop when I began assembling, at the beginning $I$ was free to experiment with color $\operatorname{mix}$ and effect.

What I eventually arrived at through my working process was a color solution where the painting would be organized by value, and the color intensity in a given area could pop. Also, I tried to include warm and cool applications of 
paint, and pasty and thin paint films to promote a textural difference. Once the painting was assembled and on the wall a clearer color relationship could be identified and then enhanced as I continued to work on it.

\section{Final Assembly}

The actual results of the painting process became clearer to me during the so called "spontaneous assembling of the paintings." It was at this point when I realized that the final assemblage would not be spontaneous at all. Nor did I realize that finding the right combination would take so much longer than making the individual parts. I had assumed that since I had a background in collage and worked intensively with found material in the past that the parts would fall together effortlessly.

The final wall constructions were made by arranging the individual canvases on the floor. After numerous movements and alignments a possible arrangement was then put on the wall. When the painting went to the wall, I could begin to see the possibilities for alteration and how it interacted with the wall. It was then that the visual weight and the balance of the piece became a point of interest and where color, value or surface could enhance or alter the final presentation.

The difficulty in arriving at a suitable arrangement, I think, lies in the compositional choice of using only 
horizontals and verticals. It is very hard to break out beyond the typical "T," "L," "J" or "U" shapes. It is the contrast in the scale of the parts that give the overall contour its interest. Importantly, the scale shift alters our perception of the weight and balance. (Imagine one of the paintings as a single color.) The color break-up of the field is subordinated to the shape contrast, but depending on the value of the intensity where color meets color, a strength or weakness in the edge occurs and affects the overall contour. In some cases, the actual edge of the canvas may look weaker than the painted edge. 
CHAPTER II

PERSONAL CONTEXT

My early training as an undergraduate was at an art school where we worked from a traditional observational curriculum. In this setting, the formal language of art was used to transform the model-the still life, figure or nature-beyond what was there or to idealize and impart, if possible, expressive content. The language itself was not considered the end, but rather the means.

Although our curriculum was largely Eurocentric, my interest, though casual at the time, turned to Asian art. I did not approach this in an organized way nor did I consider this a reawakening of a deeply repressed heritage. In comparison, the Asian art looked so refreshing and clear next to late Rococo and early 19th century painting. I just tried to look at as much Asian art as I could. Specifically, I was interested in Japanese ceramics, prints and crafts.

In retrospect, three specific characteristics of Japanese art come to mind which probably made the transition from traditional observational art to non-objective art smooth and logical. First, the distinction between fine art and craft is not so strong in Asian art. The art object is 
widely accepted as a significant cultural artifact. Second, there seemed a greater attention to the inherent properties of the materials. The material wasn't always subordinated to the will of the artist or rather it didn't look that way. Finally, "the gesture" was considered a sign of "Zen emptiness," rather than willful control.

All of these characteristics worked their way into my sensibility, which at the time sought an uncluttered, uncomplicated thinking process. It was then that I began setting up systems for working in which the limitations of the process would partly determine the outcome. One question regarding process comes to mind: If the process determines the outcome of the work, then where does personal choice come into play? How does one evaluate the processoriented work in terms of expressive content?

I think that one ultimately relies on intuition to make the final decisions about the validity of a work or art. I realize, however, that my intuition is highly conditioned, both by education and by the formal constraints of the medium; it is a sort of hot-house intuition. I believe that the important thing in process art is a willingness to allow painting to happen and to accept the real issues of the painting rather than to project one's will on it. 
CHAPTER III

\section{THE PAINTINGS}

$\underline{5 \% \neq 50 \%}$

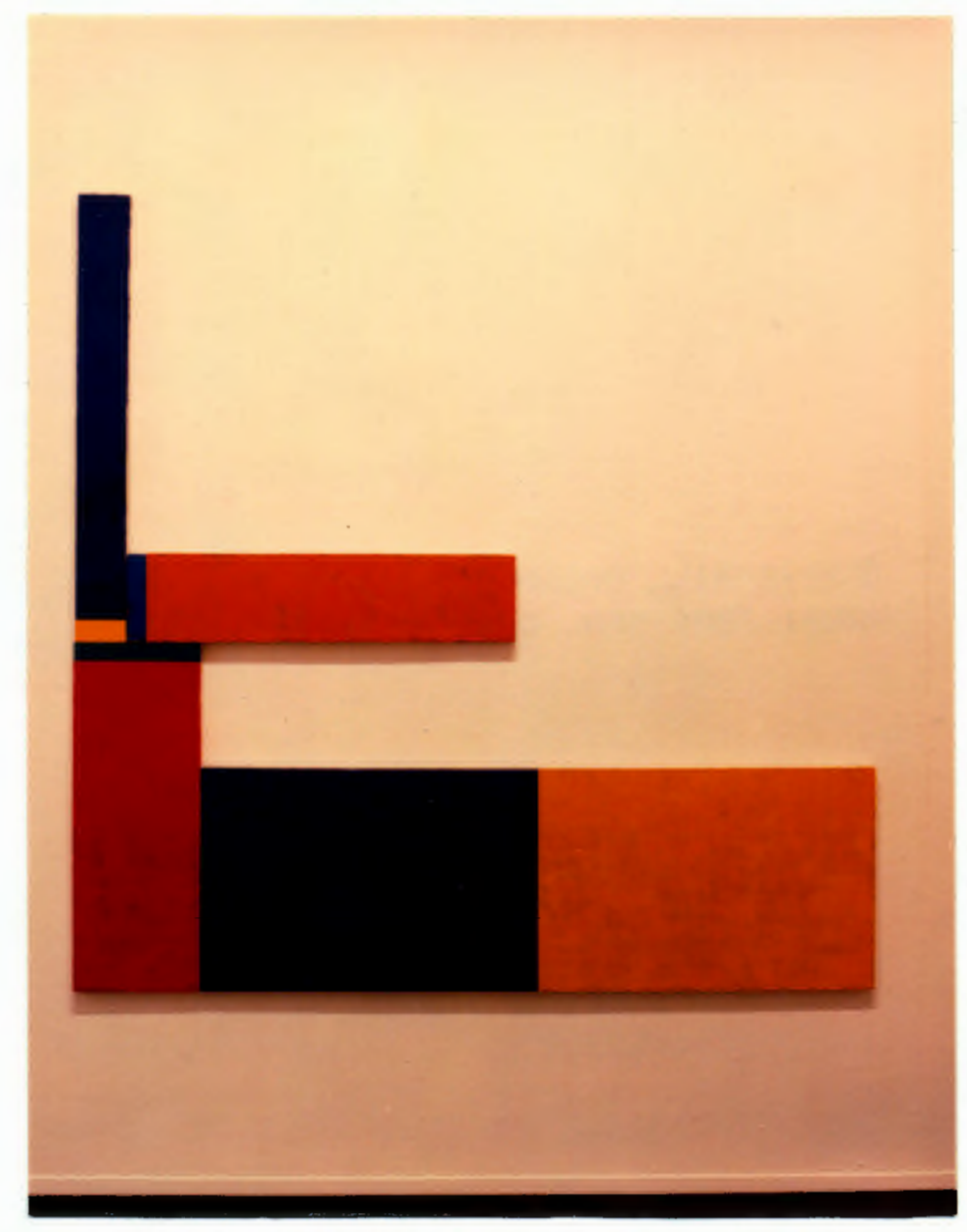

Figure 2. 5 \& $\not 50 \%\left(75^{\prime \prime} \times 75^{\prime \prime}\right)$.

This seminal painting suggests the direction the other paintings would follow. It employs many of the concepts of 
contrast I tried to promote in my working method.

The painting is made of four individual canvases. The "found" proportion of each of the canvases was arrived at through the process of building. I had made several long rectangular shapes and I wanted to use all of the extra lumber. The narrowest rectangle was an experiment to try to build something very thin but still remaining a shape. Each shape is a variation on the long rectangle.

I had begun to use the statistical information for dividing the canvases and I didn't have a lot of data to work with, so I made my divisions at 5\% which is the percentage of the U.S. population to the total world population. The remaining canvas, which was divided in half, was something I had left over from the previous year. I had assembled the three smaller canvases with the intention of trying to animate and extend the form. The subdivision in the canvases began as initial contrasts of the individual parts, but as I put the pieces together the differences became exaggerated. The larger blue and yellow rectangle happened to be leaning against the wall. The red, yellow and blue association seemed obvious.

It is a coincidence that the height and the width are about the same. (However, all lengths are coming out of one uniform eight foot length.) The strength of the left vertical and the intensity of the color offsets or counterbalances the weight of the larger areas of blue and 
yellow. Although the shape of the piece suggests a square and our eye fills in the rest, it is the orange bar that interacts with the negative space of the wall.

\section{Untitled \#1}

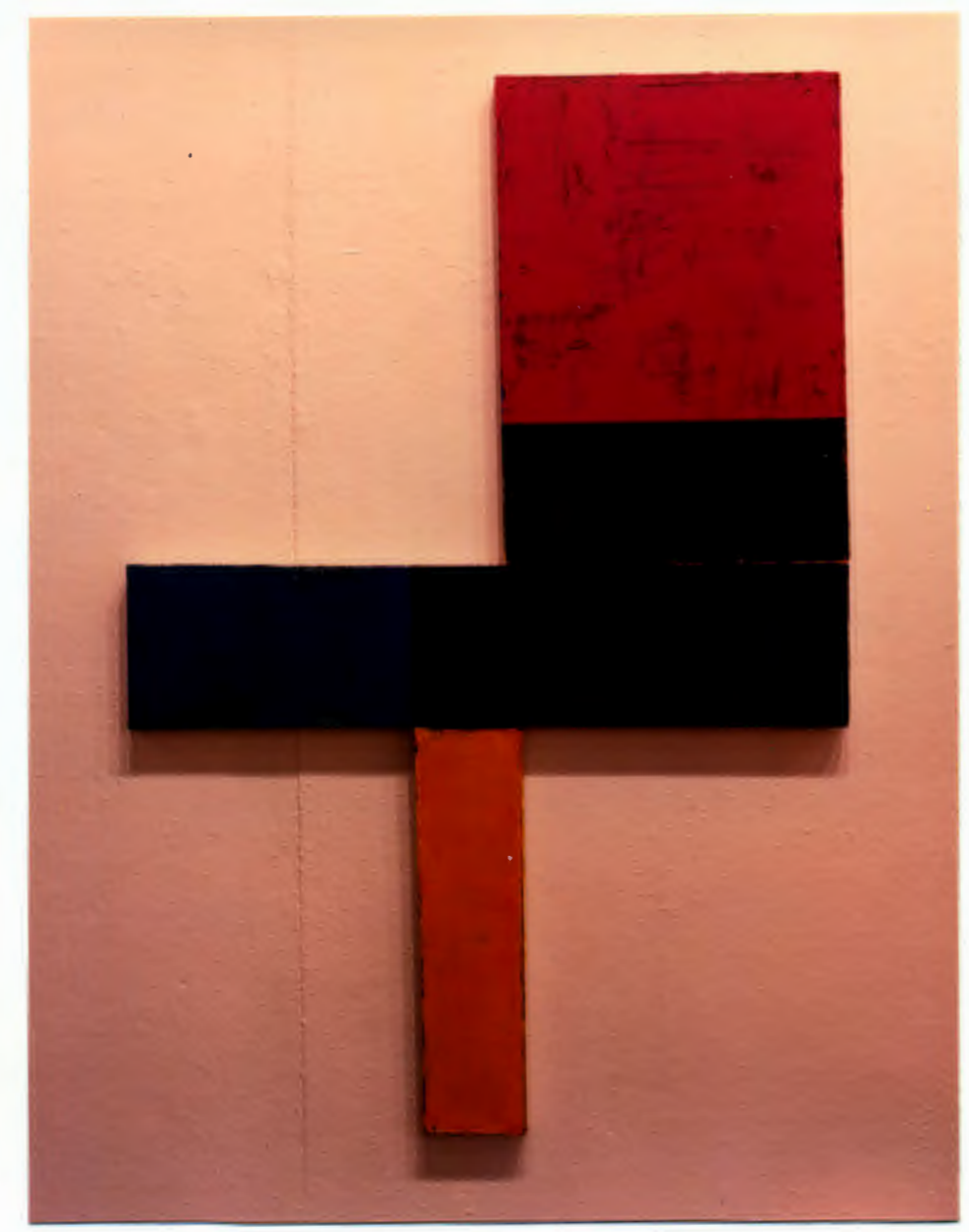

Figure 3. Untitled \#1 (31 1/2" $\times$ 59").

I categorize this painting with $\underline{5 \% \neq 50 \%}$ because the supports are thin and it employs contrasts of surface and shape and includes a variation on red, yellow and blue. More importantly, this painting shares a similar expansive 
composition and attempts to direct the visual weight which gives the painting an off-balance feeling.

\section{Untitled \#6}

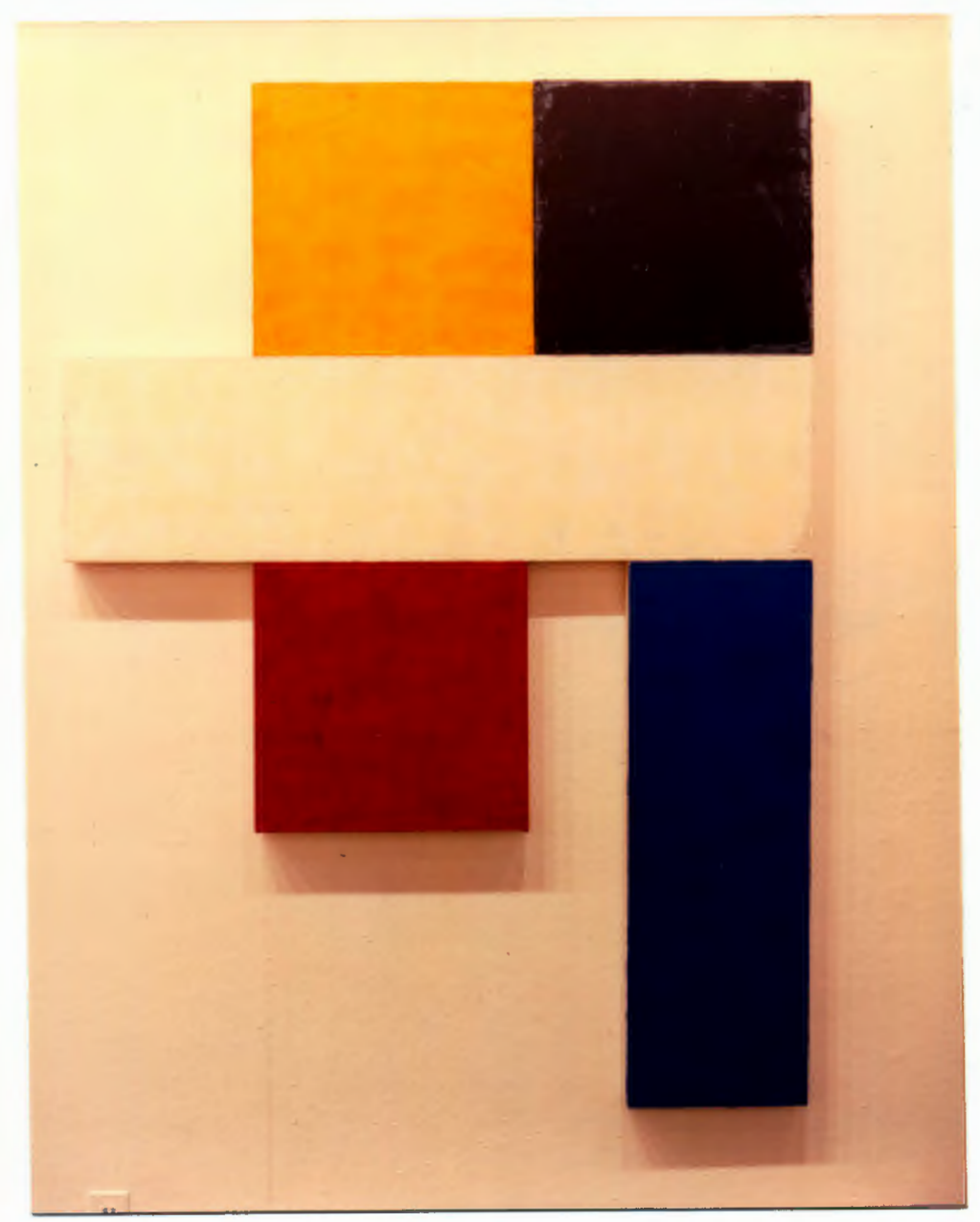

\section{Figure 4. Untitled \#6 (48" $\times 67 ")$.}

This painting does not have the statistical subdivision. It still uses red, yellow and blue plus black and white. I began to use warm and cool paint applications and some of the panels are atmospheric while others are 
opaque. I used thicker supports and the compositions begin to lose the expansive quality and turn in on itself.

\section{Untitled \#3}

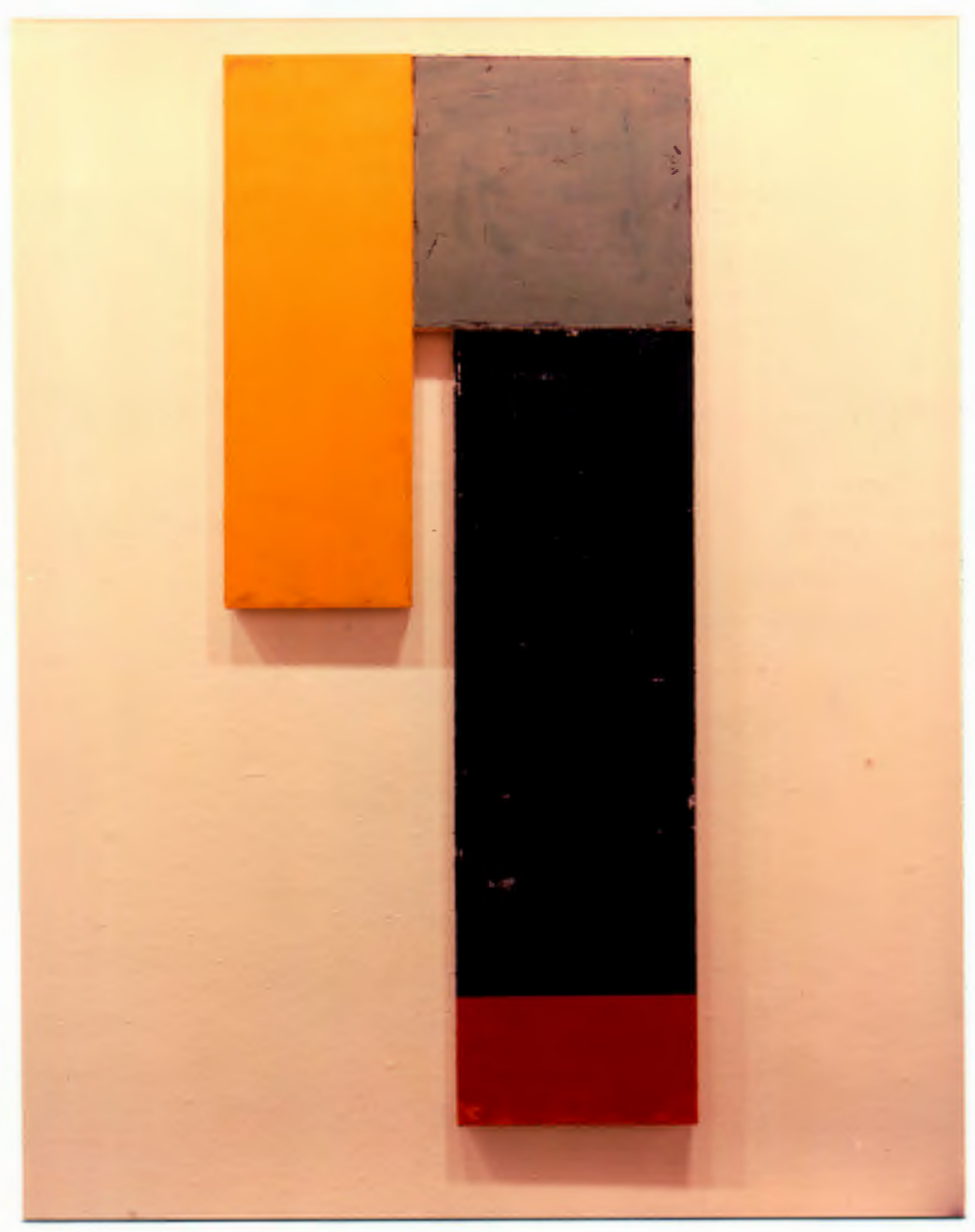

Figure 5. Untitled $\# 3$ (30" $\left.\times 70^{\prime \prime}\right)$.

Untitled $\# 3$ shares a similar upside-down hook shape that began with untitled $\# 6$. It is a much simpler painting, but I feel this is compensated for by the contrasts in the surface application and the textural quality of the paint. 
Although I consider this still a red, yellow and blue painting, the red is more orange or rust, the yellow is uncharacteristically opaque and the blue is more like a dye or an ink.

\section{Untitled \#5}

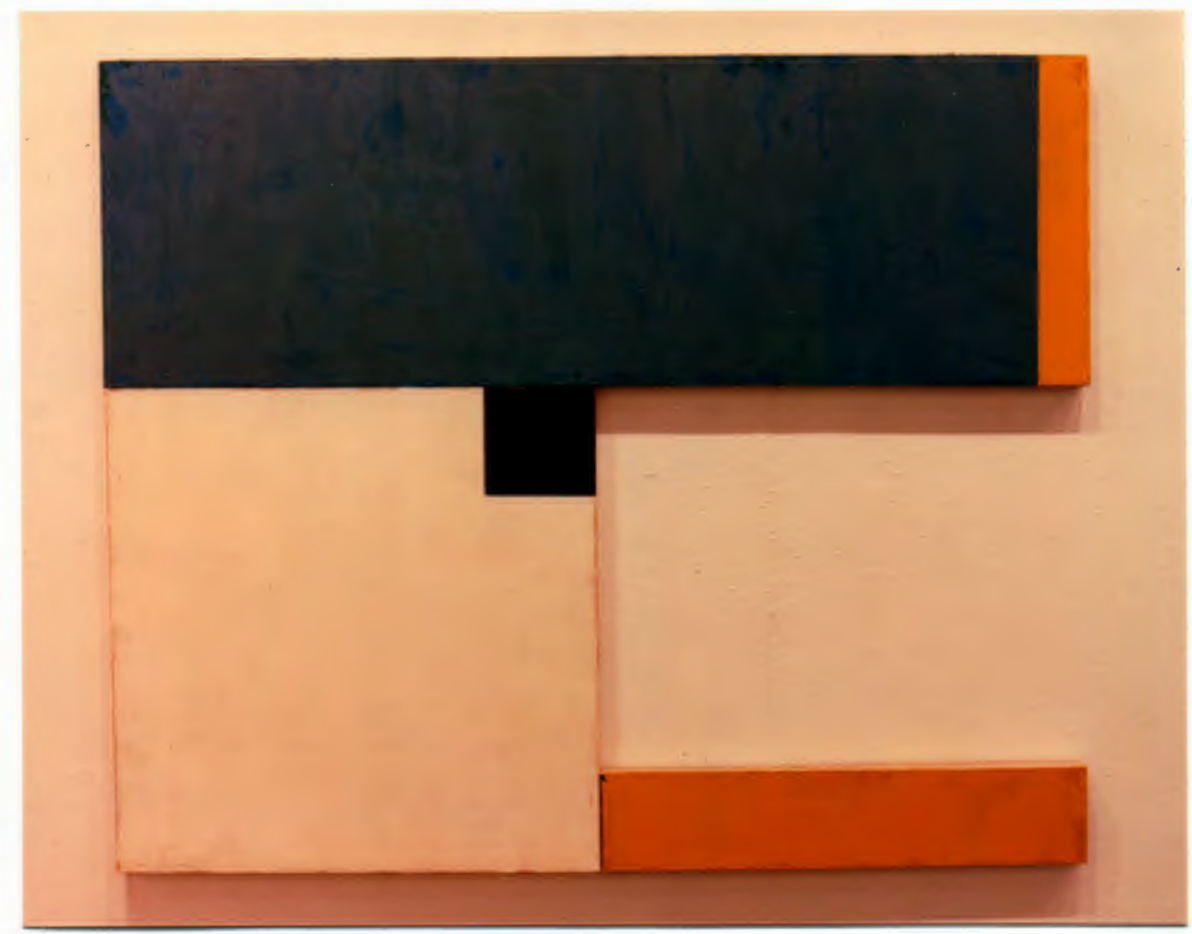

Figure 6. Untitled \#5 $(571 / 2 " \times 60 ")$.

This painting takes the hook shape further to create an almost closed rectangular shape. The blue and the black seem to form one single shape that nests in the white canvas. Although the surface contrasts are played down, there exists a contrast between the strength of the painted edge and the weakness of the actual edge. 


\section{Baby Got Back}

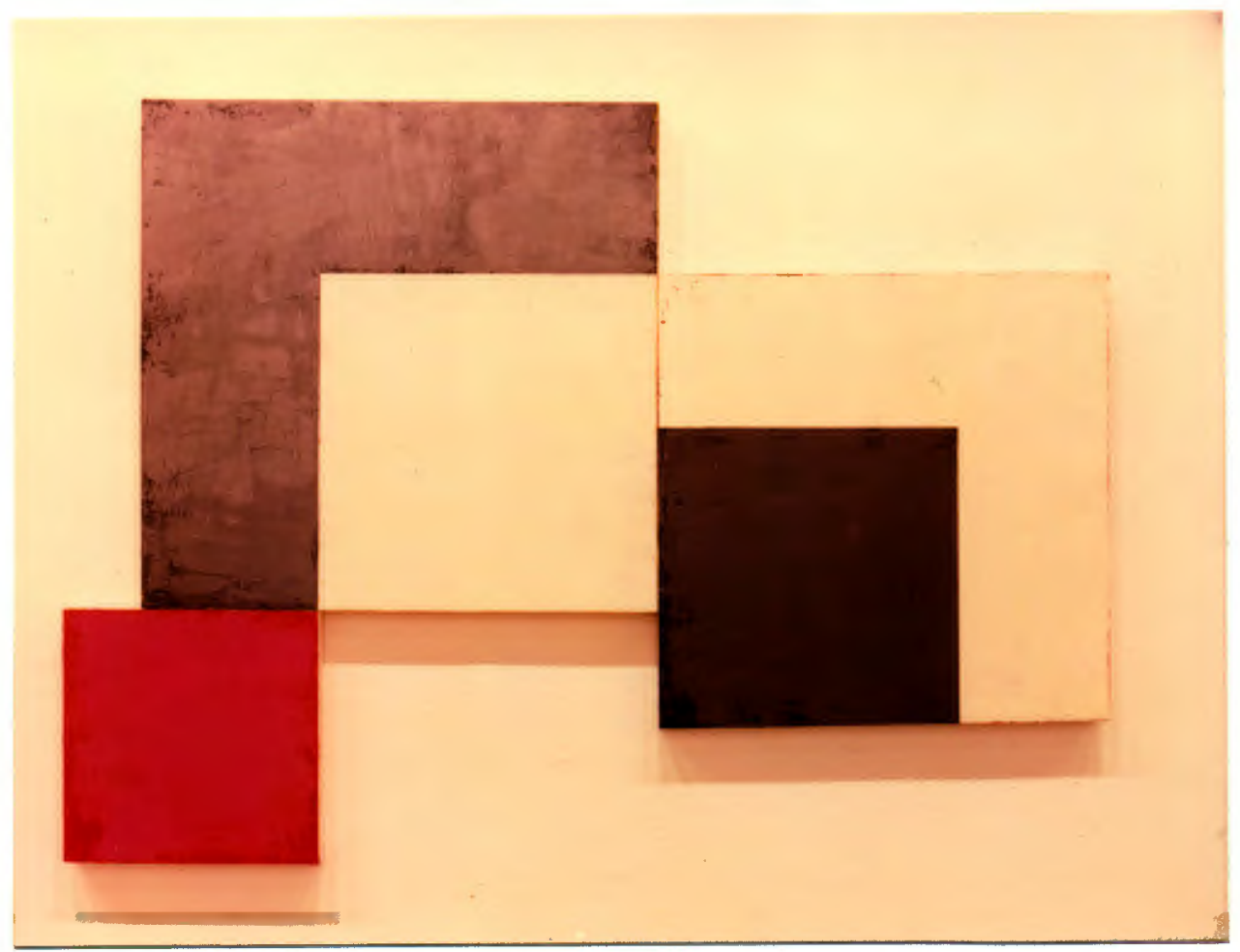

Figure 7. Baby Got Back ( $73^{\prime \prime} \times 533 / 4^{\prime \prime}$ ).

Although this has strong alignments in the compositions, it is not hook shaped nor is it activated by a contrast in shape. In fact, it is composed of squares with square subdivisions. The "L" shapes wrap around the squares and connect the left and right sides. Because the subdivisions occur on the edge of the canvases and the color contrasts are so strong, there seems to be an ambiguity between a figure/ground composition and a flatter, interlocked shape composition. 


\section{Untitled \#7}

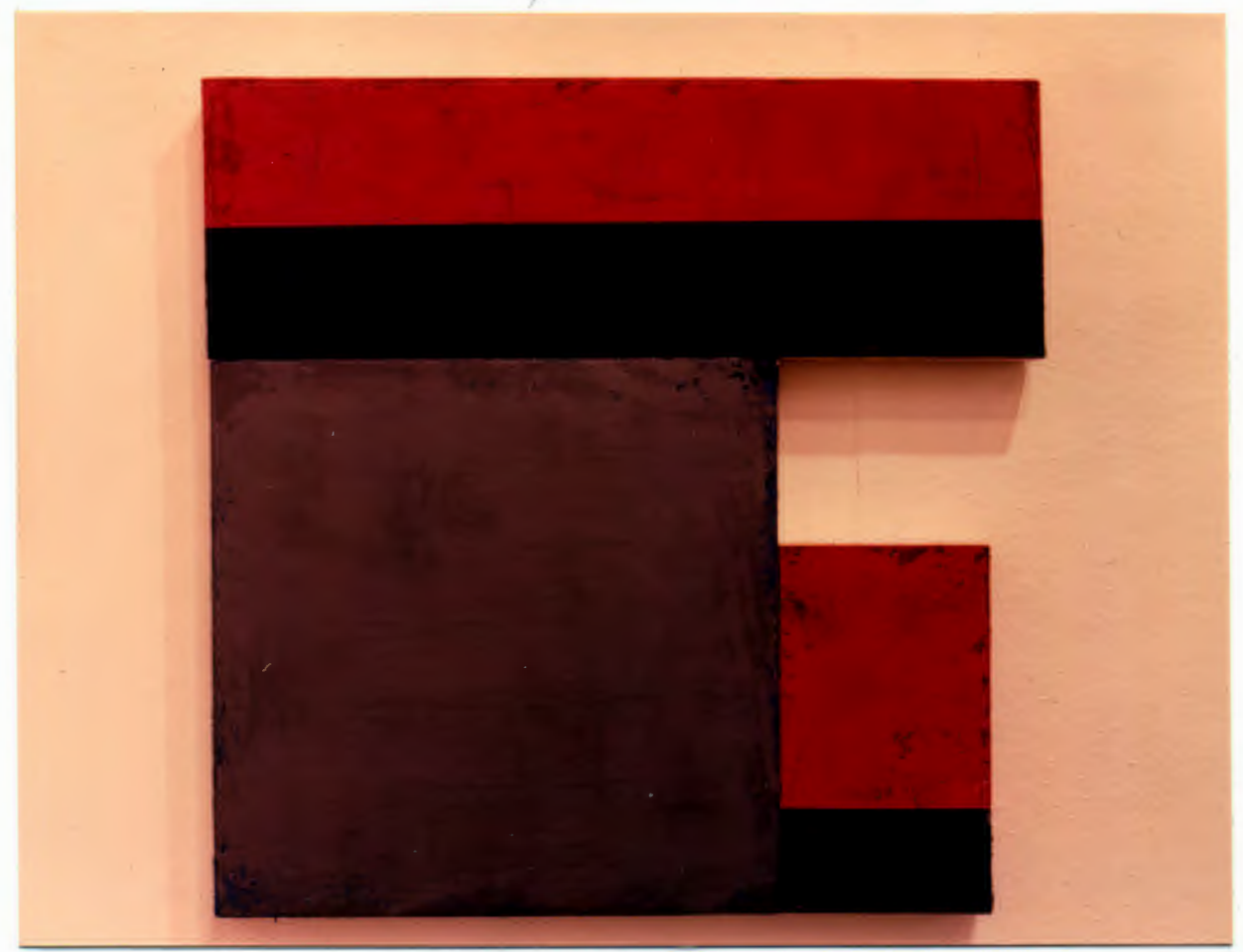

Figure 8. Untitled \#7 (35 1/2" x 36").

This is the last painting I made. Perhaps because it is smaller and differences are not as prominent, it seems weaker to me. I think the painting could be improved by reworking the color and value and altering the parallel horizontal line of the magenta and black.

\section{CONCLUSION}

It is difficult to determine the success of the paintings. In retrospect, I would probably continue to make changes. From the vantage point of even two months, I can see where, for example, scale and surface could be promoted 
further or differently. However, this could be another set of paintings altogether.

My overall concern with regard to a thesis project, is the quality of the experience and the response to the ideas put forth in the paintings. In this sense, I have been fortunate to work with the people I worked with and I am grateful for the opportunity to pursue a difficult idea intensively

Eva Hesse has said "Art is an essence, a center. I am interested in solving an unknown factor of art and an unknown factor of life." Whether these problems are solvable or not, it not for me to judge. However, through the gradual accumulation of understanding we prepare ourselves in the event that we might find a solution along the way. 